\title{
Child Abuse: The Human Figure Drawing Test in Evaluating Minors
}

\author{
Andrea Lisi, Stallone Valentina, Tomasino Maria Giovanna, Affatati Valeria and \\ Ignazio Grattagliano*
}

\begin{abstract}
Department of Criminology and Forensic Psychiatry, University of Bari, Italy
Abstract: The Human Figure Drawing Test (HFDT) is widely used in clinical and forensic settings. The inappropriate use of this instrument is widespread. This article highlights the expressive and communicative value of children's drawings in child abuse investigations. The drawings of 3 groups of children ( 11 certified as abused; 11 suspected of being abused, and 11 certified as non-abused) were examined in order to determine the appropriateness of their use in suspected cases of child abuse. The results of our study appear to be divergent. As of the writing of this article, there is no methodologically correct way in which to utilize this instrument that would reveal specific "graphic indicators of abuse" using the drawings of abused, or presumably abused children.
\end{abstract}

Keywords: Human Figure Drawing Test (HFDT), abuse investigation, child abuse, graphic abuse indicator.

Interacting with a child who has been traumatized by alleged sexual violence during the course of legalmedical and forensic psychiatric evaluations is no easy task. These children encounter great difficulty when confronted by legal authorities in the recalling and recounting of traumatic experiences. For these reasons, and with the aim of accommodating the youngster's pain during the gathering of useful information regarding the alleged abuse, it is necessary to employ techniques that show the greatest possible respect for the young victim and the experience that he or she has endured. Certain graphic products are often used under such circumstances in an attempt to help these children to externalize emotions and memories which are too threatening to be verbalized, as well as to bring repressed memories to the surface in order to overcome their sense of powerlessness, hidden fears, and anxieties. These instruments may also help them to vent anger, aggression, and hostility. In such cases, the drawing is a useful, efficient, non-intrusive, and indirect instrument that allows for the expression of subconscious traumatic memories. It also facilitates the processing of these memories and aids in cognitive reorganization. In addition, it can provide an outline for associating their confused emotional states and for integrating fragmented thoughts and feelings (Machover, 1949; Malchiodi, 1997; Pynoos \& Eth, 1985; Spring \& Cohen, 1987; Steele, 1997; Greco, Curci, Grattagliano, 2009; Bastianoni, P., Taurino, A., 2012; Margari, Pinto, Lafortezza, Craig, Grattagliano, Maragari, 2013). Ultimately, it permits them to express

*Address correspondence to this author at the Sezione di Criminologia, Padiglione Medicina Legale Universitaria Facoltà Medicina e Chirurgia Università degli Studi di Bari, Policlinico, Piazza Giulio Cesare Bari 70124 Italy; Tel: +39 335629 6185; Fax: +39 080547 8248;

E-mail: i.grattagliano@criminologia.uniba.it their emotions by way of a picture that uses a method that is both visual and motoric (Burgess \& Hartman, 1993), hence, it is stimulating on visual, tactile, and kinesthetic levels (Malchiodi, 2001). In addition, this type of instrument is useful for understanding the emotional and cognitive dimensions of the child so as to build a trusting rapport with the professional, "to break the ice" as it were, promoting dialogue and putting these youngsters, who are particularly defensive and anxious, at ease in anxiety-inducing clinical or judicial settings. This method is a much less threatening modality for the expression of emotions and thoughts allowing the rational channel to be bypassed, thereby circumventing the subject's defenses, feelings of shame, guilt, and mistrust, which is often the case when dealing with an allegedly abused minor (Ionio \& Procaccia, 2003). Moreover, the drawing encourages verbalization and the recounting of events: even very specific details that might otherwise remain hidden, for example, knowledge of the human body or details regarding the juvenile's life and social relationships. But due to its particular technicalinterpretive features, even though the drawing allows for greater subjective expression, it is more difficult to codify responses. For these reasons, the validity of the graphic images produced using these instruments in the field of expert testimony is the object of controversy and contradictory empirical results.

With regard to the doubts pertaining to the validity of this instrument, various authors (Gulotta, 1997; Kelley, 1984; Thomas \& Silk, 1990) recommend caution in the interpretation of material in the projective key_because it lacks a standardized protocol, objective scoring procedures that guarantee reliability (Gulotta, 1997; Hagwood, 1992; Palmer et al., 2000), and is 
psychometrically limited, or rather, has low validity, low reliability, no established margin of error, and cannot be generalized Di Nuovo, 2002; Hammer \& Kaplan, 1966; Hibbard \& Hartman, 1990a, 1990b). In addition, the Human Figure Drawing Test shows itself to be vulnerable to variables such as the child's level of motivation and interest, graphic abilities and attitudes towards drawing, the ability to draw, and other aspects related to the social-cultural background of the child. (Goodenough \& Harris, 1950; Oliverio Ferraris, 1973).

Moved to do so by their experience in expert testimony and clinical expertise, the authors have chosen to analyze the Human Figure Drawing Test, beginning with an examination of the numerous criticisms raised regarding methodological aspects of this instrument in the area of expert testimony, particularly in cases where reliable and accurate testimony from a juvenile victim of maltreatment and abuse is required. This work attempts to shed light on the expressive and communicative value that the drawing may assume in cases involving child victims of sexual, physical and psychological abuse, as well as neglect.

With the aim of establishing support for the hypothesis that drawings by abused and maltreated children can provide unequivocal indicators of abuse experienced, some authors (Burgess, 1988; Chantler, Pelco, \& Mertin, 1993; Cuthbertson \& Revel, 1987; Goodwin, 1982; Hibbard \& Hartman, 1990a; Hjort \& Harway, 1981; Joiner, Schmidt, \& Barnett, 1996; Manning, 1987; Prino \& Peyrot, 1994; Yates, Beutler, \& Crago, 1985) have dedicated themselves to the study of drawings by these victims.

A review of the literature has shown how it is possible to find recurring themes from the drawings of abused children. By analyzing children's drawings, many researchers (Anfossi, 1998; Burgess, McCausland, \& Wolbert, 1981; Cohen-Liebman, 1995; Faller, 1988; Malchiodi, 1997; Trowbridge, 1995), have worked in an attempt to draft lists of possible graphic indicators, structural elements of abuse, and its perception, though many questions still remain open and unanswered.

Children's pictures are linked to variables connected to adoptive strategies used by the child in a situation of abuse, including its duration and frequency, the child's age, and the identity of the abuser (Malchiodi, 2000). For this reason it is difficult to compile a list of welldefined indicators; nonetheless, Cohen-Liebman
(1995), Malchiodi (1997) and Trowbridge (1995) believe that it is possible to identify a common symbolic language from the contents, forms, colors, characteristics, and subjects found in children's drawings:

- $\quad$ Sexually explicit images: Depictions of genitals, nude figures, exaggerated make-up, long eyelashes, and/or a pronounced tongue (Anfossi, 1998; Burgess et al., 1981; CohenLiebman, 1995; Di Leo, 1970; Drachnik, 1994; Faller, 1988; Hibbard, Roghmann, \& Hoekelman, 1987; Kelley, 1984; Malchiodi, 1990; 2000; Yates et al., 1985). Various contributions to the literature (Burgess et al., 1981; Hibbard et al., 1987; Koppitz, 1968; Miller, Veltkamp, \& Janson, 1987; Yates et al., 1985) show that the spontaneous depiction of genitals in children's drawings is quite rare, and is an element that may be correlatable to having been sexually abused, or to having undergone a surgical intervention on the genitals.

- Incomplete depiction of the human body: Absence of one or more important elements of the body schema (e.g. feet, hands, legs, or trunk) (Anfossi, 1998; Cohen \& Phelps, 1985; Cohen-Liebman, 1995; Goodwin, 1982; Kelley, 1984; Malchiodi, 1997).

- Accentuation of the size of the arms and legs (Kelley, 1984).

- Depiction of only the head or the upper part of the body: Enriched with many details: a graphic indicator of avoidance or denial of the body, which is experienced as dirty, mutilated, or damaged due to the abuse experienced (Anfossi, 1998; Kelley, 1984; Sidun \& Rosenthal, 1987).

- $\quad$ Fragmented depiction of the body: Head separated from the body, or body parts floating and not connected to each other, interpreted as the desire of the victim not to recognize his body as his own (Spring, 2001).

- $\quad$ Missing eyes: Interpreted as withdrawal from the self and difficulty in having contact with the external world, as well as a subconscious desire not to see (Anfossi; 1998).

- Eyes separated from the body: Indicator connected to a feeling of guilt that the minor may 
experience due to the self-perception of having provoked the abuse (Spring, 2001).

- $\quad$ Disorganized body schema: The human figure is represented in way typical of a lower developmental stage with respect to the child's chronological age. The figure appears to be poorly articulated or has ambiguous features (Malchiodi, 2000). The author associates this element of the disfigured drawing to the idea that abused children have a distorted body image resulting from the trauma experienced.

- $\quad$ Presence of heart shaped images and circular figures: Drawn in a traditional and stereotypical way, or as images attached to clothing (Cohen \& Phelps, 1985; Malchiodi, 1990; 2000; Sidun \& Rosenthal, 1987; Spring, 2001). These images could be interpreted as indicators of powerlessness, of repetitive behaviors, mulling over, an absence of a behavioral planning, and a lack of control that a sexually abused child experiences (Spring, 2001).

- $\quad$ Inadequate use of graphic space: Partial use of space on paper, overlapping of objects, filling of the paper in a compulsory manner, use of space beyond the paper's borders, use of lines, spots of color (Anfossi, 1998; Cohen-Liebman, 1995; Miller et al., 1987; Whol \& Kaufman, 1985).

- $\quad$ Encapsulation: Representation of fencing which separates the people or objects from other elements in the drawing (Cohen-Liebman, 1995; Malchiodi, 1990), or any other element within the drawing where the child includes a representation of himself (Cohen \& Phelps, 1985).

- $\quad$ Compartmentalization: Subdivision and placement of each graphic representation in a carefully delineated space, used as symbolic defense, or rather, as a means of protection against danger (Cohen-Liebman, 1995).

- Atypical pressure exerted on the paper: (Hagwood, 1994; Sidun \& Rosenthal, 1987; Whol \& Kaufman, 1985). Sidun and Rosenthal (1987) have shown that juvenile victims of abuse present with elevated levels of anxiety and tension, the reason for which they more frequently use particularly heavy strokes.

- $\quad$ Excessive erasing and the complete absence of the child in the drawing: Indicative, according to some authors (Hjorth \& Harway, 1981; Whol \& Kaufman, 1985; 1992), of uncertainty, indecision, and general dissatisfaction.

- $\quad$ Limited range of colors: With a prevalence of black and/or red (Anfossi, 1998; Malchiodi, 1990; 1997; 2000; Spring, 1988). Red is associated with feelings of anger, and black with depressed feelings.

- Use of colors in an abstract way rather than realistic: A combination of complimentary colors (Cohen \& Phelps, 1985; Cohen-Liebman, 1995; Malchiodi, 1990; Spring, 1988) that seems to be associated with difficulty in visualization of the drawing.

- $\quad$ Legs very close to each other: Indicating an attempt at controlling sexual impulses or the worry of a possible sexual assault by other people (Hibbard \& Hartman, 1990a).

- $\quad$ Large hands: May indicate aggression or actingout behaviors (Hibbard \& Hartman, 1990a).

Even though these indicators are present in the drawings of sexually abused children, they may also be found in the drawings of children who have not been sexually abused (Malchiodi, 2000). Montecchini (1994), in a study conducted on abused children (the majority of whom were sexually abused), demonstrated how all of the subjects represented body schema in a sufficiently adequate way. It must also be pointed out that the studies that sought to identify specific graphic indicators of sexual abuse from children's drawings showed low reliability upon retest due to the variability of the drawings (Hammer \& Kaplan, 1966). In addition they also had low inter-rater agreement (Cohen \& Phelps, 1985), low internal validity (Hibbard \& Hatman, 1990a; Koppitz, 1984; Sidun \& Rosenthal, 1987), and small samples (Thomas \& Silk, 1990). Moreover, the drawings appear to be interpretable from only one qualitative perspective, and therefore are subjective in nature (Hargreaves, 1978; Palmer et al., 2000), because, as seen in the literature, they lack an objective scoring procedure. The results that have emerged from experimental and clinical studies do not allow for a value to be assigned to children's drawings that might identify maltreatment based on graphic signs (Veltman \& Brown, 2002).

This work attempts to take stock of the use of this instrument in evaluating cases of presumed abuse of minors, by thoroughly analyzing the reasons that 
support and justify its use by consultants who are called to appropriately transfer the elements that come from a purely clinical setting to one of forensic relevance. The authors would also like to underscore which elements this instrument is actually capable of bringing out during psychodiagnostic investigations, and those elements that it is not able to bring out. To this end, an exploratory study was carried out.

\section{METHODOLOGY}

The authors have analyzed the drawings of children who underwent evaluations at the Department of Criminology and Forensic Psychiatry of the University of Bari (Italy) for suspicion of abuse (sexual, physical, psychological, and neglect) and compared them to the results of other studies on this subject. The authors created a specially designed grid of selected graphic indicators taken from scientific contributions found in both the Italian and international literature, 33 human figure drawings created by minors from both sexes between the ages of 4 and 17 years and subdivided into three distinct groups were examined and codified:

Group A: 11 minors (6 females and 5 males): "certified victims" of abuse from cases in which sentences were handed down by the courts for abuse.

Group B: 11 minors (6 females and 5 males): "suspected victims" of abuse resulting from trials where the defendant was ultimately acquitted.

Group C: 11 minors ( 6 females and 5 males): the control group.

An additional subdivision was created according to age: 10 minors between the ages of 4 and 6 years; 8 minors between 7 and 10 years of age; and 15 minors 11 years of age or older. The distribution of minors in the three groups, based on the various age categories, was as follows: Group A: 4 minors $4-6$ years; 3 minors 7-10 years; and 4 minors 11 years and older. Group B: 3 minors 4-6 years; 4 minors 7-10 years; 4 minors 11 years and older. Group C: 3 minors 4-6 years; 3 minors $7-10$ years; 5 minors 11 years and older.

The methodological choice was made to not study the "Hypotheses of abuse", as is often reported in the Italian and international literature (Camisasca, 2003; Hibbard et al., 1987; Peterson, Hardin \& Nitsch, 1995), but rather only proceedings where sentences were delivered (i.e. on the final sentences handed down).
The records for each trial analyzed were requested by the District Attorney's Office. These involved cases where the University of Bari was asked to provide professional consultations. The Human Figure Drawing Test (HFDT) was one of a battery of psychodiagnostic tests used in these evaluations.

For the minors in Group A, the sentences handed down were based on guilty verdicts, after all avenues of appeal had been exhausted. For group B, however, these involved cases that resulted in acquittal or dismissal. One element on which particular attention was focused was the "stress" factor. While the subjects in Groups A and B underwent the same procedures for determining abuse, and therefore experienced the same judicial and emotional "stress", the minors in Group C (the control group) had not endured experiences of this nature.

The authors utilized a specially constructed grid for the analysis of the drawings that consisted of 68 "graphic indicators". These indicators were made up of previously drawn images and selected based on their greater or lesser significance according to the Italian and international literature on the topic of sexual abuse, as well as those involving other types of abuse such as physical, psychological, and neglect.

The 68 indicators are associated with such aspects as graphic features (e.g. pressure, type of line drawn, erasure, blackening, etc.), form (e.g. placement of figure on the paper, encapsulation, compartmentalization, etc.), content (e.g. size of the figure, omission or accentuation of body parts, the presence of genitals, objects, etc.), and emotional elements (e.g. neutrality, wellbeing, malaise, hostility of the figure represented).

\section{DATA ANALYSIS}

A statistical survey was carried out using Chi Square $\left(X^{2}\right)$ analysis with $p \leq 0.05$, comparing the presence or absence of the 68 graphic indicators with respect to sex and age, examining both the individual groups as well as the relationships between the three groups.

The codification of the drawings by way of the grid required a period of training for the observers. The calculation of inter-observer agreement for all samples under consideration resulted in an agreement percentage of $99 \%$ (calculated as: $\mathrm{N}^{\circ}$ Agreements/ Total $N^{\circ}$ Indicators x 100). 


\section{RESULTS}

Of the 68 variables considered, only the following ones resulted as significant: "Self placed in the lower portion of the drawing"; "Figure of the opposite sex"; "Presence of self attributes"; "Wellbeing"; "No color"; and "Disproportional body parts".

The graphic indicator "Self placed in the lower portion of the drawing" was reproduced by $63.6 \%$ of the children in Group B and by $18.2 \%$ of those in Groups A and $C\left(X^{2}=4.7 ;\right.$ g.d.I. $\left.=1 ; p<0.05\right)$. With regard to age, these results were only confirmed in those children between the ages of 4 and 6 years: The minors in Group B reproduced these indicators in $100 \%$ of cases, whereas the minors of the same age, in Groups A and $C$, reproduced them in $25 \%$ of cases $\left(X^{2}=3.95\right.$; g.d.I. $=$ $1 ; p<0.05)$.

The graphic indicator "Figure of the opposite sex" was reproduced $54.5 \%$ of the time by the minors in Group B, and $9.1 \%$ of the time in Group A ( $X^{2}=5.232$; g.d.I. $=1 ; p<0.025)$.

The graphic indicator "Presence of self attributes" (those, for example, that used designer names, status symbols, technological objects, stylish clothing, wellcoiffed hairstyles) was reproduced by $72.7 \%$ of subjects in Group C, and by $18.2 \%$ of subjects in Group A $\left(x^{2}=6.6 ;\right.$ g.d.I. $\left.=1 ; p<0.01\right)$. With regard to age, these results were seen in those 11 years or older: The children in Group C reproduced these indicators in $100 \%$ of cases; Minors of the same age in Group A however, drew them $16.7 \%$ of the time $\left(X^{2}=\right.$ 7.65; g.d.I. $=1 ; p<0.01)$.

The graphic indicator "Wellbeing" was reproduced $81.8 \%$ by subjects in Group C, and $36.4 \%$ by subjects in Group B ( $X^{2}=4.7 ;$ g.d.I $\left.=1 ; p<0.05\right)$.

With regard to the graphic indicator "No color", $45.5 \%$ of subjects in Group C demonstrated a substantial tendency (even though not statistically significant) towards using color in the drawings with respect to those in Group A, who did so in $9.1 \%$ of cases $\left(X^{2}=3.66 ;\right.$ g.d.I. $\left.=1 ; p=0.059\right)$.

In relation to the graphic indicator "Disproportional body parts", only those children 11 years and older in Group A reproduced it in $83.3 \%$ of cases, whereas those in the same age range in group $C$ exhibited this in $20 \%$ of cases $\left(x^{2}=4.42 ;\right.$ g.d.I. $\left.=1 ; p<0.05\right)$.
When the groups were compared, no statistically significant differences were identified with respect to the indicators examined.

\section{DISCUSSION}

Certain elements that are worthy of attention have emerged from our exploratory investigation. Firstly, of the 68 "indicators" analyzed, only six were found to be statistically significant: 1) "Self placed in the lower portion of the drawing", that is to say the drawing was done in the lower half of the paper; 2) "Figure of the opposite sex", meaning that the drawing of a subject, ostensibly of the opposite sex of the child, was rendered; 3) "Self attributes", intended as a representation of elements such as jewelry, clothing accessories, prints on clothing, etc.; 4) "Wellbeing", meant as a representation of posture and expression indicative of a state of serenity and tranquility, for example a relaxed expression, or smiling face; 5) "No color", the use of only a pencil and absent of colors; 6) "Disproportional body parts", representing disharmony between various parts of the body, for example a large head and short limbs, short trunk and short limbs, etc.

Minors in Group B more frequently reproduced the indicator "Self placed in the lower portion of the drawing" with respect to minors in Group A and Group $\mathrm{C}$, who did so with the same frequency. This value is particularly evident in minors between the ages of 4 and 6 years. It is important to point out here how this indicator may not be considered as a "graphic indicator of abuse", since the minors in which abuse had been established reproduced it with the same frequency as those who had not been abused and who had not experienced judicial stress (Group C).

It has likewise emerged that the minors in group B more frequently reproduced the indicator "Figure of the opposite sex" with respect to minors in Group A. Although the depiction of a person of the opposite sex is considered to be a relevant theme in the literature, Patterson et al. (1995) excluded it as a graphic indicator of sexual abuse. Our results also lead us to conclude that this indicator is barely linkable to verified cases of abuse since it is reproduced for the most part by children who have experienced judicial stress, but where no abuse has been established.

The minors in Group C more frequently reproduced the indicator "Self attributes" with respect to those in Group A. This value is particularly significant $(p \leq$ 
$0,001)$ for those 11 years and older. Various authors (Arace \& Giani Gallino, 2003; Giani Gallino, 2000; Warner, 1977) have shown how the enhancement of the self in the drawing, using these elements, is very common in normative samples; an absence of detail and characteristics, however, is often seen in drawings of neglected and abused children. In addition, the depiction of the self "lacking in attributes, or rather, lacking those graphic elements that enhance the features of the individual by way of attention to detail" is more frequently observed in neglected children (Arace \& Giani Gallino, 2003: 51). This has also been confirmed by the results of this study, which show a higher presence of "attributes" and, therefore, a more positive and more enriched self-image in minors who have never endured any judicial stress or abuse.

The graphic indicator "Wellbeing" was also more frequently reproduced by the children in Group $C$ with respect to those in Group B. This could lead one to the conclusion that the minors who had not suffered the stress related to an abuse investigation have a tendency to produce details related to experiences of wellbeing, tranquility, and serenity (e.g. posture, or facial expressions) in their drawings. In reference to the graphic indicator "No color", the studies conducted by Burgess (1988) highlighted how sexually abused children tended not to use colors in their drawings. It is interesting to note that there was also a significant tendency in our study with respect to the "no color" indicator with regard to group A, which had a higher frequency than Group C. A greater frequency of this indicator was found in minors who were 11 years or older. Nevertheless, the results obtained $(p=0.059)$ are slightly higher than the value $p \leq 0.05$. Consequently, it can be hypothesized that these data may vary according to sample size. Moreover, the statistical analysis of age highlights that the indicator "Disproportional body parts" is reported more frequently among those children 11 years or older in Group A when compared to Group C. In the literature, this characteristic is associated with a graphic-expressive modality typical of a lower developmental stage. In cases involving abuse, such a regressive feature would be more frequent and linkable to traumatic events connected to the abuse: In fact, abused children tend to experience their body as defaced due to the trauma endured, resulting in a reflex of regression and disorganization in the drawing (Malchiodi, 2000) Therefore, violence and abuse directed toward the body can bring about alterations in body image and poor integration of the psychic self, transmitted through a distorted representation of body schema (Koppitz, 1968; Piperno \& Di Biasi 2005; Warner, 1977). It seems opportune to point out how this indicator may also be connected to emotional conflicts related to physiological development in adolescence (Passi Tognazzo, 1991), a feature that must be evaluated very carefully as it might omit possible experiences of abuse.

Statistical analysis of gender did not show any significant difference with relation to the various graphic indicators considered in this study. In any event, it must be stressed that the results of this study must be read keeping in mind the small size of the sample: And it is for this reason they cannot be generalized. The authors recognize the need for further study with larger samples. Furthermore, a more in-depth analysis concerning the significance of the stress variable related to the environmental context in which the abuse took place is needed. Because the source of this information is non-clinical and comes from expert testimony, we opted for the methodological choice to only consider judicial stress.

\section{CONCLUSIONS}

This exploratory study on the adequacy or inadequacy of the HFDT as a graphic instrument used in the search of "abuse indicators" has revealed that it is not possible to identify specific graphic and pathognomonic elements of abuse on a minor, thus confirming what is already expressed in the SINPIA (Società Italiana di Neuropsichiatria dell'Infanzia e dell'Adolescneza) guidelines (2007). From the results obtained it was only possible to appraise the highest frequency of only some of the graphic indicators (i.e. "Self placed in the lower portion of the drawing"; "Presence of self attributes"; "Figure of the opposite sex"; "Wellbeing"; "No color"; and "Disproportional body parts"). Nevertheless, these data do not allow for the absolute determination of which children are victims of abuse and which children are not. Moreover, in some cases (e.g. "Figure of the opposite sex") our results actually show discordance when compared to other previous studies (Peterson et al., 1995), further bearing out the argument that there are no graphic indicators directly linkable to a verified case of abuse. In light of these observations, it is therefore possible to conclude that the HFDT appears to be inadequate in the search for "unequivocal signs of abuse" 
Nevertheless, it must not be forgotten that the HFDT, together with other graphic products, is a necessary integrative technique for interviewing children and is often a useful aid in the gathering of information from children and in the evaluation of those called upon to give testimony (Cohen-Liebman, 1999). From this perspective, such an instrument may not be used in judicial cases as "proof" of abuse suffered (Veltman \& Browne, 2002). And lastly, even though the HFDT has something to offer, some methodological weaknesses have been revealed, among which is the need to keep in mind the limitations of the instrument in order not to commit the error of asking the test to offer more than it is effectively capable of offering, as there is the risk of dangerous repercussions within the judicial context. To this end, it is suggested that this instrument not be used as a singular test as it may only provide useful clues for further investigation which would be carried out using other, more valid instruments (Thomas \& Jolley, 1998).

It is appropriate to stress here that, due to its psychometric and statistical weakness, in addition to increasing its reliability and validity, it would be advisable to avoid using drawings as personality tests wherever possible because in the fields of forensics and legal medicine, as well as in the clinical environment, it is difficult to establish a relationship between the psychological relevance of the drawing with the characteristics of the individual. (Bruening, Wagner \& Johnson, 1997; Cuthbertson \& Ravel, 1987; Di Leo 1973; Gulotta, 1997; Hagwood, 1992; Hibbard et al., 1987; Hibbard \& Hartman, 1990a, 1990b; Hjort \& Harway, 1981; Koppitz, 1984; Malchiodi, 2000; Montecchi, 1994; Palmer et al., 2000; Peterson et al., 1995; Spring, 2001; Veltman \& Browne, 2002; Yates et al.,1985).

\section{ACKNOWLEDGEMENTS}

The authors would like to thank Michael Kolk for his help in the preparation of this manuscript.

\section{REFERENCES}

Anfossi, M. (1998). L'abuso sessuale intrafamiliare: come lo vivono e lo rappresentano i bambini abusati. In T. GIANI GALLINO (Ed), A come Abuso, Anoressia, Attaccamento, ... Rappresentazioni mentali nell'infanzia e nell'adolescenza. Torino: Bollati Boringhieri.

Arace, A., \& Giani Gallino, T. (2003). Abuso emotivo e grave trascuratezza: la rappresentazione mentale della famiglia nei minori deprivati. Maltrattamento ed abuso all'infanzia, 5, 2, 35-56.
Bastianoni, P., Taurino, A., (2012) Teorie, Metodi e interventi. Clinica e ricerca nelle comunità per minori (special issue), Psicologia Clinica dello Sviluppo, anno XVI, 1, pp. 133-153

Bruening, C.C., Wagner, W.G., \& Johnson, J.T. (1997). Impact of rater knowledge on sexually abused and non abused girls' scores on the Draw A Person: Screening Procedure for Emotional Disturbance (DAP:SPED). Journal of Personality Assessment, 68, 3, 665-677. http://dx.doi.org/10.1207/s15327752jpa6803 12

Burgess E. (1988). Sexually abused children and their drawings. Archives of Psychiatric Nursing, 2, 65-73.

Burgess, A.W., \& Hartman, C.R. (1993). Children's drawings. Child Abuse and Neglect, 17, 161-168. http://dx.doi.org/10.1016/0145-2134(93)90015-W

Burgess, A.W., MC Causland M.P., \& Wolbert, W.A. (1981). Children's drawings as indicators of sexual trauma. Perspectives in Psychiatric Care, 19, 50-57. http://dx.doi.org/10.1111/j.1744-6163.1981.tb00110.x

CAMISASCA, E. (2003). II disegno: strumento di comunicazione nei casi di abuso all'infanzia. Focus Monotematico. Maltrattamento e Abuso all'Infanzia, 5, 2, 7-10.

Chantler, L., Pelco, L., \& Mertin, P. (1993). The psychological evaluation of child sexual abuse using the Louiseville Behaviour Checklist and Human Figure Drawing. Child Abuse and Neglect, 17, 271-279. http://dx.doi.org/10.1016/0145-2134(93)90046-8

Cohen, F.W., \& Phelps, R.E. (1985). Incest markers in children's artwork. Arts in Psychoterapy, 12, 265-283. http://dx.doi.org/10.1016/0197-4556(85)90040-1

Cohen-Liebman, M.S. (1995). Drawings as judiciary aids in child sexual abuse litigation: a composite list of indicators. The Arts in Psychotherapy, 22, 5, 475- 483. http://dx.doi.org/10.1016/0197-4556(95)00037-2

Cohen-Liebman, M.S. (1999). Draw and Tell: Drawings within the context of child sexual abuse investigation. The Arts in Psychotherapy. 26, 3, 185-194. http://dx.doi.org/10.1016/S0197-4556(99)00013-1

Cuthbertson, F.M., \& Revel, A.C. (1987). Graphic characteristics on the Draw- A-Person test for the identification of physical abuse. Art Therapy, 7, 78-83.

Di Leo, J. (1970). Young children and their drawings. New York: Brunner/Mazel.

Di Leo, J. (1973). I disegni dei bambini come aiuto diagnostico. (Tr. It. Firenze: Giunti Barbera, 1988).

Di Nuovo, S. (2002). Radiografie della mente? II punto sui test proiettivi. Psicologia Contemporanea, 174, 4-11.

Drachnik, C. (1994). The tongue as a graphic symbol of sexual abuse. Art Therapy: Journal of the American Art Therapy Association, 1, 1, 58-61.

Faller, K. (1988). Child sexual abuse: an interdisciplinary manual for diagnosis case management and treatment. New York: Columbia University Press.

Giani Gallino, T. (2000). Famiglie 2000. Scene di gruppo con interni. Torino: Einaudi.

Goodenough, F.L., \& Harris D.B. (1950). Studies in the psychology of children's drawing: II. 1928-1949. Psychological Bulletin, 47, 369-433. http://dx.doi.org/10.1037/h0058368

Goodwin, J.G. (1982). Use of drawings in evalueting children who may be incest victims. Children and Youth Services Review, 4, 269-278. http://dx.doi.org/10.1016/0190-7409(82)90004-4

Greco R.,Curci A., Grattagliano I., Juvenile criminality: General Strain Theory and the reactive-proactive aggression trait, Rivista di Psichiatria, 44, 5,328-336 
Gulotta, G. (1997). Le fonti di errore nelle valutazioni di abuso sessuale. In L. de Cataldo Neuberger (Ed), Abuso sessuale di minore e processo penale: ruoli e responsabilità. Padova: Cedem.

Hagwood, M.M. (1992). Diagnosis or dilemma: Drawings of sexually abused children. Art Therapy, 11, 11, 37-42.

Hammer, M., \& Kaplan, A.M. (1966). The reliability of children human figure drawings. Journal of Clinical Psychology, 22, 316-319. http://dx.doi.org/10.1002/1097-4679(196607)22:3<316::AIDJCLP2270220322>3.0.CO;2-N

Hargreaves, A. (1978). Towards a theory of classroom coping strategies. In L. Barton \& R. Meighan (Eds.), Sociological Interpretations of schooling and classrooms. Driffield: Nafferton Books.

Hibbard, R.A, \& Hartman, G.L. (1990a). Emotional indicators in Human Figure Drawings of sexually victimized and non abused children. Journal of Clinical Psychology, 46, 211-219. http://dx.doi.org/10.1002/1097-4679(199003)46:2<211::AIDJCLP2270460215>3.0.CO:2-C

Hibbard, R.A, \& Hartman, G.L. (1990b). Genitalia in human figure drawings: Childrearing practices and child sexual abuse. Journal of Pediatrics, 116, 822- 828. http://dx.doi.org/10.1016/S0022-3476(05)82680-0

Hibbard, R.A., Roghmann, K., \& Hoekelman, R.A. (1987). Genitalia in children's drawings: An association with sexual abuse. Pediatrics, 79, 129-137.

Hjort, C.W., \& Harway, M. (1981). The body image of physically abused and normal adolescents. Journal of Clinical Psychology, 37, 863-866. http://dx.doi.org/10.1002/1097-4679(198110)37:4<863::AIDJCLP2270370433>3.0.CO;2-A

Ionio, C., \& Procaccia, R. (2003). Comunicare il trauma: I disegni dei bambini vittime di abuso sessuale. Maltrattamento e Abuso all'Infanzia, 5, 2, 57-85.

Joiner, T.E., Schmidt, K.L., \& Barnett, J. (1996). Size, detail, and line heaviness in children's drawings as correlates of emotional distress: (more) negative evidence. Journal of Personality Assessment, 67, 127-141. http://dx.doi.org/10.1207/s15327752jpa6701_10

Kelley, S.J. (1984). The use of art therapy with sexually abused children. Journal of Psychosocial Nursing and Mental Health, 22, $12-18$.

Koppitz, E.M. (1968). Psychological evaluation of children's human figure drawings. New York-London: Grune and Stratton.

Koppitz, E.M (1984). Psychological evaluation of human figure drawings by middle school pupils. New York: Grune \& Stratton.

Machover, K. (1949). Personality projection: in the drawing of a human figure. Springfield, IL: Charles $\mathrm{C}$ Thomas Publisher. http://dx.doi.org/10.1037/11147-000

Manning, T.M. (1987). Aggression depicted in abused children's drawings. The Arts in Psychoterapy, 14, 15-24. http://dx.doi.org/10.1016/0197-4556(87)90031-1

Malchiodi, C.A. (1990). Breaking the silence: art therapy with children from violent homes. New York: Brunner/Mazel.

Malchiodi, C.A. (1997). Breaking the silence: art therapy with children from violent homes (rev. ed.). New York: Brunner/Mazel.

Malchiodi, C.A. (2000). Capire $i$ disegni infantili. Torino: Centro Scientifico Editore.

Malchiodi, C.A. (2001). Using drawing as intervention with traumatized children. Journal of Trauma and Loss, 1, 1, 2128.

Margari L., Pinto F., Lafortezza, M.E., Craig, G., Grattagliano I., Zagaria G., Margari F., Mental health in migrant schoolchildren in Italy: Teacher-reported behavior and emotional problems, Neuropsychiatric Disease and Treatment, 2013, 9, 231-241.

http://dx.doi.org/10.2147/NDT.S37829
Miller, T.W., Veltkamp, L.J., \& Janson, D. (1987). Projective measures in the clinical evaluation of sexually abused children. Child Psychiatry and Human Development, 18, 4757.

http://dx.doi.org/10.1007/BF00706529

Montecchi, F. (1994). Gli abusi all'infanzia. Dalla ricerca all'intervento clinico. Roma: La Nuova Italia Scientifica.

Oliverio Ferraris, A. (1973). I/ significato del disegno infantile. Torino: Boringhieri.

Palmer, L., Farrar, A.R., Valle, M., Ghahary, N., Pannella, M., DE Graw, D. (2000). An investigation of the clinical use of the house-tree-person projective drawings in the psychological evaluation of child sexual abuse. Child Maltreatment. 5, 2, 169-175. http://dx.doi.org/10.1177/1077559500005002008

Passi Tognazzo, D. (1991). Metodi e tecniche nella diagnosi della personalità. Firenze: Giunti Barbera.

Peterson, L.W., Hardin, M., \& Nitsch, M. (1995). The use of children's drawings in the evaluation and treatment of child sexual, emotional, and physical abuse. Archives of Family Medicine. $4,5,445-452$. http://dx.doi.org/10.1001/archfami.4.5.445

Piperno, F., \& Di Biasi, S. (2005). La rappresentazione mentale della famiglia nei bambini maltrattati e abusati sessualmente. Psicomotricità, 9, 24-43.

Prino, C.T., \& Peyrot, M. (1994). The effect of child physiccal abuse and neglect on aggressive, withdrawn, and prosocial behaviour. Child Abuse and Neglect, 18, 871-884. http://dx.doi.org/10.1016/0145-2134(94)90066-3

Pynoos, R., \& Eth, S. (1985). Developmental perspective on psychic trauma in childhood. In C.R. Figley (Ed), Trauma and its wake: the study and treatment of post-traumatic stress disorder. New York: Brunner/Mazel.

Sidun, N.M., \& Rosenthal, R.H. (1987). Graphic indicators of sexual abuse in a Draw-A-Person tests of psychoatrically hospitalized adolescents. The Arts of Psychoterapy, 14, 2533.

http://dx.doi.org/10.1016/0197-4556(87)90032-3

Spring, D. (1988). Sexual abuse and post-traumatic stress reflected in artistic symbolic language (Doctoral Dissertation). The Fielding Institute, University Microfilms, International, 4405, 9002893.

Spring, D. (2001). Image and mirage. Art therapy with dissociative clients. Sprigfield: Charles C. Thomas Publisher.

Spring, D., \& Cohen, F. (1987). The symbolic language of the sexually abused: research outcome. Paper presented at the Conference of the American Art Therapy Association, Miami.

Steele, B. (1997). Trauma response kit: short-term intervention model. Grosse Pointe Woods, Ml: Institute for trauma and loss in children.

Thomas, G.V., \& Jolley, R.P. (1998). Drawing conclusions: A reexamination of empirical and conceptual bases for psychological evaluation of children from their drawings. Journal of Clinical Psychology, 37, 127-139. http://dx.doi.org/10.1111//.2044-8260.1998.tb01289.x

Thomas, G.V., \& Silk, A.M.J. (1990). An introduction to the psychology of children's drawings. Hervester/Wheatsheaf, Hemel Hempstead.

Trowbridge, M.M. (1995). Graphic indicators of sexual abuse in children's drawings: a review of the literature. The Arts in Psychoterapy, 22, 5, 485-493. http://dx.doi.org/10.1016/0197-4556(95)00052-6

Veltman, M.W.M., \& Brown, K.D. (2002). The assessment of drawings from children who have been maltreated: Systematic review. Child Abuse Review, 11, 19-37. http://dx.doi.org/10.1002/car.712 
Warner, S.L. (1977). Understanding the effects of child abuse. Radiologic Technology, 9, 29-38.
Yates, A., Beutler, L., \& Crago, M. (1985). Drawings by child victims of incest. Child Abuse and Neglect, 9, 183-189. http://dx.doi.org/10.1016/0145-2134(85)90010-9

Received on 15-02-2013

Accepted on 04-04-2013

Published on 25-04-2013

DOI: http://dx.doi.org/10.6000/1929-4409.2013.02.11

(C) 2013 Lisi et al.; Licensee Lifescience Global.

This is an open access article licensed under the terms of the Creative Commons Attribution Non-Commercial License (http://creativecommons.org/licenses/by-nc/3.0/) which permits unrestricted, non-commercial use, distribution and reproduction in any medium, provided the work is properly cited. 